\title{
The reintroduction of the Eurasian otter (Lutra lutra) into the Netherlands: hidden life revealed by noninvasive genetic monitoring
}

\author{
H. P. Koelewijn • M. Pérez-Haro • H. A. H. Jansman • \\ M. C. Boerwinkel $\cdot$ J. Bovenschen - D. R. Lammertsma • \\ F. J. J. Niewold • A. T. Kuiters
}

Received: 17 August 2009/Accepted: 12 January 2010/Published online: 9 February 2010

(C) The Author(s) 2010. This article is published with open access at Springerlink.com

\begin{abstract}
The last recorded presence of the Eurasian otter (Lutra lutra) in the Netherlands dates from 1989 and concerned a dead individual. In 2002 a reintroduction programme was started, and between June 2002 and April 2008 a total of 30 individuals (10 males and 20 females) were released into a lowland peat marsh in the north of the Netherlands. Noninvasive genetic monitoring based on the genetic profiles obtained from DNA extracted from otter faeces (spraints) was chosen for the post-release monitoring of the population. To this end, the founding individuals were genotyped before release and spraints were collected in the release area each winter from 2002 to 2008. From June 2002 to April 2008 we analysed the genetic profile of 1,265 spraints on the basis of 7-15 microsatellite loci, 582 of which (46\%) were successfully assigned to either released or newly identified genotypes. We identified 54 offspring ( 23 females and 31 males): the females started to reproduce after 2 years and the males after 4 years. The mating and reproductive success among males was strongly skewed, with a few dominant males fathering two-thirds of the offspring, but the females had a more even distribution. The effective population size $(\mathrm{Ne}$ ) was only about $30 \%$ of the observed density $(N)$, mainly because of the large variance in reproductive success among males. Most juvenile males dispersed to surrounding areas on maturity, whereas
\end{abstract}

H. P. Koelewijn ( $\square) \cdot$ M. Pérez-Haro ·

H. A. H. Jansman - M. C. Boerwinkel · J. Bovenschen .

D. R. Lammertsma · F. J. J. Niewold · A. T. Kuiters

ALTERRA-Wageningen UR, Centre for Ecosystem Studies,

P.O. Box 47, 6700 AA Wageningen, The Netherlands

e-mail: hanspeter.koelewijn@wur.nl

Present Address:

M. Pérez-Haro

Borbón $153^{\circ} 4^{\mathrm{a}}$, 08031 Barcelona, Spain juvenile females stayed inside the area next to the mother's territory. The main cause of mortality was traffic accidents. Males had a higher mortality rate (22 out of 41 males (54\%) vs. 9 out of 43 females (21\%)). During winter 2007/08 we identified 47 individuals, 41 of which originated from mating within the release area. This study demonstrates that noninvasive molecular methods can be used efficiently in post-release monitoring studies of elusive species to reveal a comprehensive picture of the state of the population.

Keywords Carnivores - DNA - Effective population · Faeces $\cdot$ Mating system $\cdot$ Parentage analysis $\cdot$ Recruitment . Sex-biased dispersal

\section{Introduction}

The last recorded presence of the Eurasian otter (Lutra lutra) in the Netherlands dates from 1989: it was a dead individual trapped in a fyke. Otter numbers had plummeted from a flourishing population in the 1930s (van Wijngaarden and van de Peppel 1970). This rapid extinction of the Dutch otter population is typical of what happened in many industrialised and densely populated Western-European countries. The factors contributing to the decline of this aquatic top predator were environmental pollution (Roos et al. 2001), an increase in road kill due to habitat fragmentation (Hauer et al. 2002a; Kruuk and Conroy 1991; Sommer et al. 2005) and incremented pressure from fisheries with fyke nets.

After the extinction of the otter in the Netherlands, there was a call for the return of this iconic species to the Dutch wetlands. In the mid-1990s measures were taken to restore natural otter habitat, improve water quality, reconstruct interconnecting corridors and build road underpasses in a 
specific area in the north of the Netherlands. It was made mandatory to use stop grids on fyke nets in this area, to reduce the risk of young otters drowning.

In 2002 a reintroduction programme was started, since it seemed unlikely that otters would recolonise spontaneously from the nearest populations in Germany in the short term. Reintroduction projects attempt to re-establish species within their historical ranges by releasing wild or captivebred individuals following extirpation or extinction in the wild (Seddon et al. 2007). They are often carried out to fulfill a biodiversity preservation or restoration objective. According to the IUCN Reintroduction Guidelines (1998), the ultimate goal of reintroduction projects should be "the establishment of a self-sustaining population that requires minimal long-term management". Several authors have pointed out that in order to achieve this goal, projects should be accompanied by "focused monitoring" to identify the possible cause of success or failure (Nichols and Williams 2006; Seddon et al. 2007; Armstrong and Seddon 2008) and that the resulting information should be used to improve future project designs.

Currently, most inferences in reintroduction biology are made by induction, gained from post hoc interpretation of monitoring results or by exploratory comparative analyses (Seddon et al. 2007). The main information needed for a long-term perspective on reintroduced populations is on the vital statistics, e.g. mortality and recruitment. This entails extensive monitoring, which is an obstacle for many projects because of its expense (Morell 2008). Yet from the many anecdotal and contradictory results (Seddon et al. 2007), it is clear that post-release monitoring is badly needed in reintroduction efforts.

Genetic monitoring, i.e. quantifying temporal changes in population metrics or other population data generated using molecular markers, is becoming increasingly important for monitoring the consequences of anthropogenic change on wild species (Allendorf and Luikart 2006; Schwartz et al. 2007; Wayne and Morin 2004). Molecular markers can be used either as a diagnostic tool for individual identification and traditional population monitoring, or for estimating changes in population genetic parameters, providing information on genetic diversity, inbreeding, effective population size or migration (Schwartz et al. 2007). Genetic data is invaluable for ecologists and wildlife managers, especially when it is combined with behavioural, demographic, or spatial information (DeYoung and Honeycutt 2005). In contrast to traditional techniques like telemetry, genetic monitoring offers advanced possibilities for the long-term monitoring of population structure. The development of noninvasive genetic procedures, i.e. extracting DNA from biological samples such as hair, faeces, or urine without handling, capturing or even observing the animals (Kohn and Wayne 1997; Taberlet et al. 1999; Piggott and Taylor 2003; Waits and Paetkau 2005) yields details on elusive and nocturnal animals like bears (Kendall et al. 2009), coyotes (Kohn et al. 1999; Prugh et al. 2005), otters (Ferrando et al. 2008; Hung et al. 2004), lynx (Palomares et al. 2002) and wolves (Creel et al. 2003). Combining genetic monitoring and noninvasive sampling into noninvasive genetic monitoring offers an excellent supplementary technique for studying the structure of reintroduced populations, as this enables timedependent processes such as trends in inbreeding and recruitment to be monitored, especially if DNA is sampled from the outset of the reintroduction.

Despite being very promising, the technique, and thereby the quality of the results, is constrained by the quantity and quality of DNA extracted from the biological samples (Miller et al. 2002; Taberlet et al. 1996). Genotyping from secondary material is prone to several problems, e.g. allelic dropout caused by the random amplification of only one of two alleles at a heterozygous locus due to the scarcity of template DNA. Another type of error, a "false allele", is an artefact generated during the amplification process, which often reveals a spurious or third allele. To ensure that estimates of abundance and individual identification are reliable, these errors need to be detected, e.g. by repeating the DNA amplifications independently several times, in order to obtain trustworthy consensus genotypes (Taberlet et al. 1996).

Though otters are elusive and nocturnal animals and are therefore hard to trace (Kruuk 2006; Mason and Macdonald 1986) they leave scent markers of their home range at prominent sites of aquatic habitats, such as bridges, logs, and sandy beaches. In our survey, which was started concomitantly with the reintroduction of the first otters into the Netherlands, we used DNA isolated from freshly deposited spraints (faeces) and anal secretions (jellies) to assess (a) the presence and distribution of the founders, (b) the recruitment of new individuals (offspring) into the population, (c) to determine the ancestry of these offspring and infer the social and genetic structure of the population, and (d) to estimate the abundance of otters in the study area during successive years. We did so in the belief that only noninvasive genetic monitoring could give us the answers to the probing questions surrounding the reintroduction of elusive animals (see Armstrong and Seddon 2008; Morell 2008; Schwartz et al. 2007). Using DNA as a tag to identify individuals we were able to build a detailed life table and a pedigree of the otter population, to evaluate the first phase of the reintroduction programme and to suggest how the reintroduction programme should be continued. 


\section{Materials and methods}

Study area

The study area comprised lowland peat marshes in the north of the Netherlands, ca. $200 \mathrm{~km}^{2}$ in extent and located at $52^{\circ} 38^{\prime}-52^{\circ} 50^{\prime} \mathrm{N}, 5^{\circ} 53^{\prime}-6^{\circ} 09^{\prime} \mathrm{E}$. The area consists of a mosaic of peat grasslands, reed beds (Phragmites australis) and swamp woodland, mainly composed of Willow (Salix spp.), Black alder (Alnus glutinosa) and Birch species (Betula spp.) intersected by small ditches and pools. Most of the surrounding landscape is intensively farmed. The mean annual temperature is $9.5^{\circ} \mathrm{C}$ and on average there are 10 frost days per year. The area can be divided into three zones: the Weerribben and the Rottige Meenthe, which comprise peat grassland, woodland and ditches, and the Wieden, where larger lakes are also present (Fig. 1).

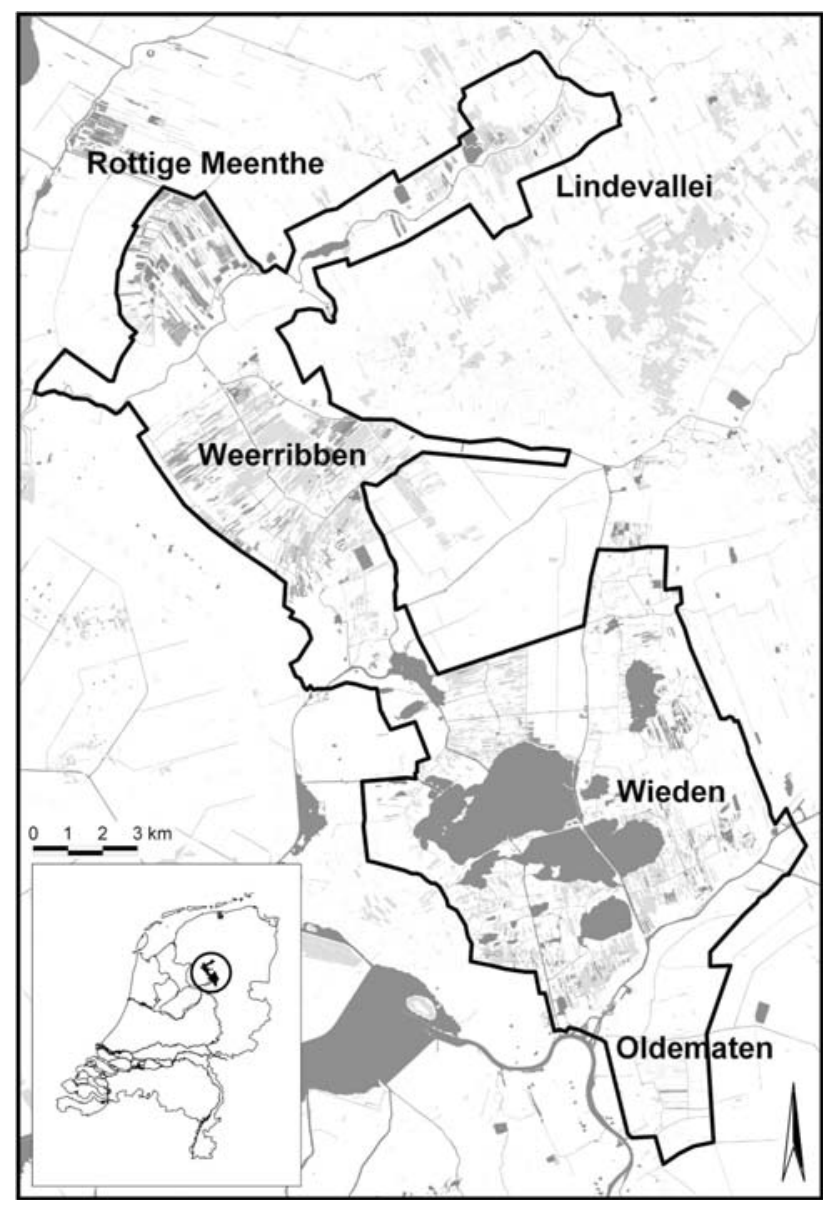

Fig. 1 Geographical location of the study area. The black border surrounds the area where 30 otters were released until 1 April 2008. The expanding population was monitored using noninvasive genetic sampling
Origin and release

The otters used in the Dutch reintroduction project had either been captured in the wild in Belarus, Latvia, or Poland, or originated from captivity or rehabilitation programmes in Sweden (Finnish origin), the Czech Republic, or Germany. The otters caught in the wild came from areas with high otter densities. Between July 2002 and April 2008, 30 otters were sequentially released in the study area (Table 1). The first set of otters was released in the Weerribben, the central location, and in subsequent years otters were gradually added to the Wieden and Rottige Meenthe areas (Table 1). At the time of release the animals varied in age between 1 and 5 years old. Before their release, tissue and blood samples were taken for DNA fingerprinting and all the otters were tagged with a transponder and were fitted with a radio transmitter, implanted intraperitoneally, for monitoring initial post-release movements and survival. The implantations were carried out by a veterinarian at Burgers Zoo (Arnhem, The Netherlands), where the otters were kept in captivity for 318 days and observed before being released. The study was conducted in accordance with Dutch legislation on the protection and welfare of vertebrate animals used for experimental and other scientific purposes.

\section{Sample collection}

Sprainting behaviour often shows seasonality and there is evidence that winter is the best period to collect otter spraints (Kruuk 1992) and that the microsatellite DNA analysis of otter faeces is most successful in cold months, when spraints are collected in the early morning (Hájková et al. 2006). During summer it is difficult to collect fresh spraints in our area because the tall grass and reeds obstruct visibility. Therefore, our surveys were carried out in the winter half year (October to the end of March) of consecutive years from 2002 to 2008.

Each winter period we checked the whole release area for otter activity (spraints, spoor, landing sites, trails). In November and December each year we did a first survey of the whole release area covering about $10-15 \mathrm{~km}^{2}$ per day by foot, bike and boat. From January to March we conducted a second survey. We tried to cover the whole release area at least twice and revisited promising sites suggested by the field managers. On average we spent 48 days in the field each winter, searching for otter marks. We tried to revisit each location from which we had collected a spraint, with the aim of obtaining at least 3 fresh spraints from that location. The constraints were the accessibility of the terrain and the availability of waterways. We used GPS to record the locations of spraints and thus ascertain the spatial organisation of the population. 
Table 1 Number of otters released until 1 April 2008

\begin{tabular}{|c|c|c|c|c|c|c|c|}
\hline Date & \# Released & Country & Origin & Release area & Female-Male & Code & $\begin{array}{l}\text { Cumulative \# } \\
\text { released }\end{array}$ \\
\hline July 2002 & 7 & $\begin{array}{l}\text { Belarus, Latvia, } \\
\text { Czech Republic, Sweden }\end{array}$ & $3 \mathrm{~W}, 4 \mathrm{C}$ & Weerribben & $4-3$ & $\mathrm{~A} 00-\mathrm{A} 06$ & 7 \\
\hline October 2002 & 4 & Belarus, Latvia & W & Weerribben & $3-1$ & A $07-A 10$ & 11 \\
\hline November 2002 & 4 & Belarus, Latvia & W & Weerribben & $2-2$ & A11-A14 & 15 \\
\hline June 2004 & 5 & Poland, Latvia & W & Wieden & $3-2$ & A15-A19 & 20 \\
\hline July 2004 & 1 & Latvia & W & Wieden & $1-0$ & $\mathrm{~A} 20$ & 21 \\
\hline November 2005 & 2 & Germany & $\mathrm{C}$ & Wieden & $1-1$ & A21, A22 & 23 \\
\hline June 2006 & 4 & Germany, Russia & $\mathrm{C}$ & Rottige Meenthe & $2-2$ & A23-A26 & 27 \\
\hline September 2007 & 1 & Germany & $\mathrm{C}$ & Wieden & $1-0$ & A27 & 28 \\
\hline November 2007 & 2 & Germany, Sweden & $\mathrm{C}$ & Rottige Meenthe & $1-1$ & A28, A29 & 30 \\
\hline Total \# released & & & & & $20-10$ & & 30 \\
\hline
\end{tabular}

Indicated are the date of release, countries of origin, origin of the animals (captive (C) or wild caught (W)), release area, number of males and females, the main coding and the cumulative number of animals released

If possible, the area was visited the day before collection and old spraints were marked to increase the chance of identifying fresh spraints the next day. When this strategy could not be employed, we collected all the spraints that seemed to be fresh. To minimise DNA degradation, spraints were collected in the morning. The samples were immediately put into $10 \mathrm{ml}$ plastic phials containing $99 \%$ ethanol and taken to the lab, where they were stored at $-20^{\circ} \mathrm{C}$ until DNA extraction and analysis. A total of 1,265 spraints were collected for genetic analysis.

We conducted a vigorous publicity campaign to encourage people to contact us when dead otters were found, so that we would have a as complete picture of the population as possible. Dead otters were delivered to Alterra throughout the year and subjected to post mortem analysis to determine the most likely cause of death. Tissue samples from the cadavers were stored in phials containing 99\% ethanol. Most of the otters brought in were road kills from outside the release area.

\section{Rationale of the monitoring design}

Since our otter population is small $(n=30$ founders $)$ and isolated, and immigration from Germany seems highly unlikely, it is effectively a closed population. At the start of the project we constructed a reference database of the genetic profiles of the founders, so that in subsequent years we could infer successful mating and recruitment from new genetic profiles obtained from spraints or dead animals. We updated the database of genetic profiles yearly. Since all potential parents were known, we applied complete exclusion as our method of parentage analysis (Blouin 2003; Jones and Ardren 2003). A spraint was classified as from an offspring if (a) the genetic profile did not match existing profiles from previous years, and (b) the profile could unequivocally be assigned to a known male and female. The offspring-mother-father combination was subsequently checked by comparing the distribution of GPS-coordinate observations of the animals involved.

\section{DNA extraction}

Faecal DNA was extracted using a modification of the hexadecyltrimethylammonium bromide (CTAB)-based extraction (Parsons et al. 1999; Hung et al. 2004). This entailed removing a spraint from the phial of ethanol and briefly putting it on filter paper to remove most of the ethanol. Next, a raisin-sized piece was put in a $2 \mathrm{ml}$ Eppendorf tube together with $1 \mathrm{ml}$ of CTAB buffer $(100 \mathrm{mM}$ Tris- $\mathrm{HCl} \mathrm{pH}$ 8, $20 \mathrm{mM}$ EDTA, $1.4 \mathrm{M} \mathrm{NaCl}, 2 \%$ CTAB) and the spraint was homogenised by stirring with a small rod. After adding additional CTAB buffer to bring the total volume to $2 \mathrm{ml}$, the mixture was briefly vortexed and left on a shaker for $15 \mathrm{~min}$. This mixture was centrifuged for $5 \mathrm{~min}$ and $1.5 \mathrm{ml}$ of the supernatant was transferred into a new tube together with $0.5 \mathrm{ml}$ chloroform. After two rounds of extraction, DNA was precipitated by adding $0.67 \mathrm{ml}$ isopropanol to $1 \mathrm{ml}$ of the cleared suspension. The resulting pellet was resuspended in $0.18 \mathrm{ml}$ of ATL buffer. Spraint pellets and tissue from released and dead individuals were further processed following the protocol of the DNeasy Blood and Tissue Kit (Qiagen) for DNA purification.

\section{Genetic typing}

During the first three winters seven microsatellites were sufficient for individual typing and parentage assessments: 
Lut701, Lut715, Lut717, Lut733, Lut818, Lut832 and Lut833 (Dallas and Piertney 1998). Subsequently because of the loss of released individuals, the occurrence of offspring and the increasing relatedness among individuals, we had to gradually increase the number of microsatellite loci: OT04, OT05, OT07, OT14, OT17, OT19 and OT22 (Huang et al. 2005) and RI18 (Beheler et al. 2005). We only used tetranucleotide microsatellite loci to reduce the occurrence of stutter bands and ambiguity in scoring that often happens with dinucleotide loci.

PCR reactions were performed in a total volume of $10 \mu$ containing 0.3 Units of Taq (Invitrogen Taq DNA polymerase (18038-034), amounts of PCR buffer and W-1 according to the Invitrogen protocol, $130 \mathrm{nM}$ of each primer, $200 \mu \mathrm{M}$ of each dNTP, $4.25 \mathrm{mM} \mathrm{MgCl} 2$ and $320 \mu \mathrm{g} /$ $\mathrm{ml}$ BSA. Forward primers were labelled with either an IRD-700 or an IRD-800. The PCR programme used was $95^{\circ} \mathrm{C} / 3 \mathrm{~min}$ and $\left(90^{\circ} \mathrm{C} / 30 \mathrm{~s}, T_{\mathrm{a}} / 30 \mathrm{~s}, 72^{\circ} \mathrm{C} / 1 \mathrm{~min}.\right) \times 39$ cycles. For most primers $T_{\mathrm{a}}$ was $60^{\circ} \mathrm{C}$, except for locus Lut715 $\left(T_{\mathrm{a}}=58^{\circ} \mathrm{C}\right)$, loci Lut733, Lut782 and Lut818 $\left(T_{\mathrm{a}}=59^{\circ} \mathrm{C}\right)$, locus Lut717 $\left(T_{\mathrm{a}}=61^{\circ} \mathrm{C}\right)$, and locus OT07 $\left(T_{\mathrm{a}}=62^{\circ} \mathrm{C}\right)$. The same protocol was used for tissue extracts, except that a dilution factor of 10 was applied and $2 \mu \mathrm{l}$ of this diluted extract was used. For sex identification we used the DBY7Ggu primer following the protocol of Hedmark et al. (2004).

PCR products of microsatellite loci and sexual typing were genotyped on a $6.5 \%$ polyacrylamide gel containing $7 \mathrm{M}$ Urea and $1 \times \mathrm{TBE}$ on a Li-Cor 4300 platform.

\section{Data analysis}

We did not use the same set of microsatellite loci every year because initially the seven loci of Dallas and Piertney (1998) had sufficient power to distinguish individuals and assess parentage. In 2006/07 these seven loci were still sufficient for identifying individuals, but not for assessing parentage. After optimising and adding the second set of loci we made two new sets of loci: (i) a set for distinguishing individuals (Lut715, Lut717, Lut733, Lut833, OT07, OT19 and OT22); and (ii) a set with the remainder of the loci, which we used solely to confirm parentage assessment or in cases of doubtful identification of an individual because of the failure of a locus. Budget constraints prevented us from using all loci. The criterion for compiling our first set of loci was a $P_{(\mathrm{ID}) \text { sib }}$ of $<0.01$. The probability of identity, $P_{(\mathrm{ID})}$, is the probability that two individuals drawn at random from a population have the same genotype at multiple loci (Creel et al. 2003; Taberlet and Luikart 1999; Waits et al. 2001). It is considered to be the most common statistic used to quantify the power of molecular markers in distinguishing two individuals. The $P_{(\mathrm{ID}) \text { sib, }}$ the $P_{(\mathrm{ID})}$ among a population composed solely of siblings, gives an upper limit to the possible range of $P_{(\mathrm{ID})}$ in a population. At the beginning of the project, in 2002/03, the $P_{(\mathrm{ID})}$ among the released animals was $1.9 \times 10^{-7}$ and the $P_{(\mathrm{ID}) \text { sib }}$ was $1.9 \times 10^{-3}$. Because of the changing population composition, e.g. loss of released individuals, presence of offspring and increased relatedness, in $2006 / 07 P_{(\mathrm{ID})}$ was $4.1 \times 10^{-6}$ and $P_{(\mathrm{ID}) \text { sib }}$ was $4.4 \times$ $10^{-3}$. During the $2007 / 08$ season the $P_{(\mathrm{ID}) \text { sib }}$ of our first set of loci was $2.1 \times 10^{-3}$, but when all 15 loci were used it increased to $1.4 \times 10^{-5}$.

To reduce the chance of mistyping, we applied a modified multiple tube approach (Gagneux et al. 1997; Hung et al. 2004; Taberlet et al. 1996). The constraint on the modified approach was that with our current protocol we could only run ca. 50 PCRs from one faecal extract and therefore had to adjust the number of replicates when using all 15 microsatellite loci. Our approach was as follows: (1) Each sample was amplified three times for locus LUT715. This locus was chosen because of good, repeatable results in previous experiments. (2) The sample was discarded from the subsequent analyses if there were less than three PCR products. In case of three PCR products a sample was still discarded if, after scoring the results, it resulted in three different typings. (3) Selected samples were amplified three times for the remaining loci from the first set. (4) Three independent typings with the same single allele at a locus confirmed a homozygote. Three independent typings with the same two alleles at a locus confirmed a heterozygote. Samples with two typings of a heterozygotes and one homozygous typing, were scored as heterozygous with the two alleles appearing in these typings. (5) For loci that were typed twice as homozygous and once as heterozygous, or for loci that were scored as homozygous for different alleles, three additional independent typings were performed. When among the six typings an allele was recorded at least twice, the sample was accepted as heterozygote. If an allele appeared only once among the six typings the sample was accepted as a possible homozygote. (6) Those samples that could not be appropriately typed up after six typing attempts were discarded. (7) When the genotypes of two samples were the same at six loci and the only mismatch at the seventh locus may have been due to allelic dropout, we considered the two samples to be the same multilocus genotype if they came from geographical locations close to each other. As safeguard, these samples were also typed for the second set of loci. If the only mismatch was an unambiguous different typing at the seventh locus, the samples were always typed for the second set of loci. (8) The consensus genotypes obtained were compared with the reference database and, if possible, assigned to known individuals. (9) In case of new profiles we tried to assess parentage and completed the profile for the remaining loci. Final parentage was assessed on 15 loci, with complete exclusion as the criterion (Blouin 2003). 
Since we had complete genetic profiles for the otters released, we calculated allelic dropouts and false alleles as deviations from the expected profile after assigning spraint samples to known individuals. The allelic dropout for a locus was computed from the number of homozygotes typed for the heterozygous individuals, divided by the total number of heterozygous samples. Allelic dropout occurred in $15.2 \%$ of the heterozygous samples and varied among loci (range: $8.1 \%$ (LUT833)-22.4\% (LUT717)). When using three independent amplifications, the probability of obtaining false homozygotes was 0.0018 , using the equation $P=K \times(K / 2)^{n-1}$ (Gagneux et al. 1997), where $K$ is the observed frequency of false homozygotes averaged over all individuals and loci and $n$ is the number of repeated amplifications. Strictly speaking, false alleles are undefined amplification products that show up as a spurious or third allele. These occurred in only $2.1 \%$ of the PCR reactions. More broadly speaking, a heterozygous typing of a homozygote individual could also be considered as a false allele. The observed frequency of false heterozygotes was $14.9 \%$ and varied among loci (range: $4.0 \%$ (LUT733)-
$26.2 \%$ (LUT717)). As expected, these values are comparable to the allelic dropout results.

\section{Results}

\section{Spraint surveys}

Of a total of 1,265 spraint samples, 582 were successfully genotyped, resulting in an overall success rate of $46 \%$ (Table 2). Our success rate gradually improved during the years as a result of refining the laboratory protocols. During the 2007/08 winter we achieved a success rate of 59\% (Table 2). The number of spraints per individual per census varied from 1 to 27, indicating considerable capture heterogeneity among individuals.

Of the 30 individuals released, only $15(50 \%)$ were reidentified from spraints (Table 2). We identified a total of 54 offspring during the period 2002-2008: 23 females and 31 males (Tables 2, 3). Of these offspring, 41 (76\%) were identified from spraints and $13(24 \%)$ as dead animals

Table 2 Summarised genetic data on otter spraints collected between October 2002 and April 2008 (a) and otters recovered dead from the same period and from which no spraint observations were known (b)

\begin{tabular}{|c|c|c|c|c|c|c|c|c|}
\hline & \multicolumn{6}{|c|}{ Winter period } & \multirow[t]{2}{*}{ Total } & \multirow{2}{*}{$\begin{array}{l}\text { Fraction of released } \\
\text { animals or observed } \\
\text { offspring }^{\text {a }}\end{array}$} \\
\hline & $2002 / 03$ & $2003 / 04$ & $2004 / 05$ & $2005 / 06$ & $2006 / 07$ & $2007 / 08$ & & \\
\hline \multicolumn{9}{|l|}{ (a) Spraints } \\
\hline Number collected & 31 & 65 & 187 & 273 & 370 & 339 & 1265 & \\
\hline $\begin{array}{l}\text { Fraction successfully } \\
\text { genotyped }\end{array}$ & 0.35 & 0.29 & 0.41 & 0.36 & 0.46 & 0.59 & 0.46 & \\
\hline $\begin{array}{l}\text { Number of } \\
\text { identified unique } \\
\text { genotypes }\end{array}$ & 4 & 10 & 11 & 17 & 22 & 37 & 56 & 0.67 \\
\hline Founders & 4 & 6 & 6 & 5 & 7 & 6 & 15 & 0.50 \\
\hline Female & 2 & 4 & 3 & 4 & 6 & 6 & 11 & 0.55 \\
\hline Male & 2 & 2 & 3 & 1 & 1 & - & 4 & 0.40 \\
\hline Offspring & - & 4 & 5 & 12 & 15 & 31 & 41 & 0.76 \\
\hline Female & - & 2 & 3 & 7 & 10 & 17 & 21 & 0.91 \\
\hline Male & - & 2 & 2 & 5 & 5 & 14 & 20 & 0.65 \\
\hline $\begin{array}{l}\text { Number of spraints } \\
\text { per genotype } \\
(\min -\max )\end{array}$ & $1-3$ & $1-6$ & $1-13$ & $1-27$ & $1-24$ & $1-19$ & & \\
\hline $\begin{array}{l}\text { Individual with the } \\
\text { most observations }\end{array}$ & M-A12 & M-A12 & $\begin{array}{l}\text { M-A12/ } \\
\text { M-A18 }\end{array}$ & M-A08 & M-NB15 & $\begin{array}{l}\text { M-NB15/ } \\
\text { M-NB30 }\end{array}$ & & \\
\hline \multicolumn{9}{|c|}{ (b) Dead offspring without known spraint signature } \\
\hline Female & - & - & - & - & 1 & 1 & 2 & 0.09 \\
\hline Male & - & - & 3 & 1 & 1 & 6 & 11 & 0.35 \\
\hline
\end{tabular}

Data are arranged according to status (founding animals and newly identified genotypes (=offspring)) and sex (female and male). Main observation period for the spraints was the winter (1 October-31 March). Dead animals were brought in throughout the year

a The number of released animals was 30 (20 females and 10 males). The number of identified offspring was 54 (23 females and 31 males) 
without previous spraint signature (Table 2). Among the offspring, the likelihood of being detected through spraints differed significantly between the sexes: $91 \%$ for the females and $65 \%$ for the males $\left(X^{2}=5.18, P=0.023\right.$; Table 2).

\section{Mating and recruitment}

We inferred a total of 30 matings and 54 offspring (Tables 3, 4). In the consecutive winter periods, an increasing number of females were involved in mating; offspring females started to mate after 2 years (Table $3 \mathrm{a}$, c). The number of males involved in reproduction was much lower and initially declined, but it increased during winter 2006/07 when the first generation of offspring males became sexually active (Table 3c). However, offspring males took twice as long as offspring females to become involved in population recruitment (Table 3a, c). The number of females a male mated with varied greatly: from one to seven (Table 3c). During winter 2005/06 only a single male (A08) contributed to the reproduction by mating with seven different females (Tables 3a, 4).

The number of offspring identified increased steadily during consecutive winters (Table 3b). The winter of 2007/ 08 saw the first third-generation offspring resulting from matings between second-generation males and females (the offspring of the founder, i.e. first generation, population) the previous year (Table $3 b, c)$.

\section{Reproductive success}

Throughout the observation period we found offspring of 16 founders (9 females and 7 males: Table 3). These founders contributed to reproduction predominantly during the early years; later they were replaced by their descendants, especially during the winter of 2006/07 (Table 3b, c). Despite the involvement of many individuals in the mating process (Table 4), reproductive success was very skewed, especially for the males (Fig. 2). When considering only those individuals that could have reached maturity by winter 2007/08, 34\% of the males observed in our population produced offspring; for the females this figure was more balanced, but still only $51 \%$ of the females became involved in successful reproduction (Fig. 2). The average number of offspring per female was $1.67 \pm 4.92$ (mean \pm variance; $n=33$ ), for the males this was $1.90 \pm 24.71(n=29)$. The high variances are indicative of the skewed distribution of reproductive success.

A large number of offspring (25 out of 54) shared the same father (A08; Table 4). This male was solely responsible for the 15 offspring observed during winter 2006/07 (Table 3b, c). After the disappearance of A08 two other males (NB11 and NB15) took over his dominant position.
The more dominant one of the two was NB15, a son of A08 (Table 4), so A08 still continued to put his stamp on the population.

Fate of the individuals

By 1 April 2008 though we still had records on the presence of $30 \%$ ( 6 out of 20 ) of the females released, we no longer had evidence that any of the ten males released were still alive. The comparable figures for the offspring females and males were 78 and 29\%, respectively (Table 5). The data shown in the alive and dead columns of Table 5 show that offspring males had a significantly higher mortality than offspring females $\left(X^{2}=12.41, P<0.001\right.$; Table 5). The majority of the dead otters delivered to Alterra were subadult males that had been found outside the release area beyond a radius of ca. $50 \mathrm{~km}$. In most instances they were traffic victims.

The fate of $43 \%$ of the otters released is unknown, the comparable figure for the observed offspring is only $12 \%$ (Table 5).

State of the population

Counting the identified genetic profiles and dead animals reveals a steady growth in the population, with individuals designated as "native-born" taking over (Fig. 3). Initially, the population hardly grew and it took 4 years before the actual population size exceeded the number of animals released. The total number of individuals identified during winter 2007/08 was 47.

\section{Discussion}

Noninvasive genetic methodology

After the initial euphoria concerning the use of noninvasively collected biological material for genetic research, the shortcomings arising from the small amounts of DNA, or the poor quality of the DNA or of the extract became clear, and a more cautious approach was advocated (Schwartz et al. 1999; Taberlet et al. 1999). Since then, much emphasis has been on the development and optimisation of lab and statistical protocols to safeguard against unjustified interpretations of the results (Bonin et al. 2004; Mills et al. 2000; Waits and Paetkau 2005). If mistakes occur in the genetic profiles due to genotyping errors caused by allelic dropouts, there is a risk of overestimating population size (Mills et al. 2000). The risk can be reduced by including fewer loci in the genotype or allowing one or two mismatches among loci, thereby reducing the probability of creating spurious genotypes. This, however, reduces the 
Table 3 (a) Reproductive patterns and number of offspring observed during the period July 2002-April 2008. (b) The number of new offspring identified during the successive winter periods, grouped according to the origin of the mother and the origin of the father. The parent otter could be a founding animal (founder) or an offspring from previous years (native-born); (c) the number of reproducing females and males during the successive winter periods. Individuals are classified according to their origin: either a founding animal (founder) or an individual born in the release area (native-born). Also shown is the range in the number of matings, i.e. different females, per male

\begin{tabular}{lllllll}
$\begin{array}{l}\text { Year of release } \\
\text { or estimated birth }\end{array}$ & Parents $(\mathrm{F} \times \mathrm{M})$ & \multicolumn{4}{l}{ Winter period during which mating took place } & $\begin{array}{l}\text { Total \# offspring } \\
\text { observed }\end{array}$ \\
\cline { 2 - 6 } & $2002 / 03$ & $2003 / 04$ & $2004 / 05$ & $2005 / 06$ & $2006 / 07$ &
\end{tabular}

(a)

Females

F-A 00

F-A01

F-A02

2002

F-A03

2002

F-A15

2004

F-A19

2004

F-A20

2004

F-A22

2004

F-A23

2005

F-NB02

2003

$\mathrm{A} 03 \times \mathrm{A} 12$

F-NB04

2003

A02 $\times$ A06

F-NB07

2004

$\mathrm{A} 03 \times \mathrm{A} 12$

F-NB16

2005

F-NB17

2005

F-NB19

2005

F-NB22

2005

F-NB32

2006

$\mathrm{A} 02 \times \mathrm{A} 08$

$\mathrm{A} 02 \times \mathrm{A} 08$

A19 $\times$ A18

$\mathrm{NB} 07 \times \mathrm{A} 08$

$\mathrm{NB} 07 \times \mathrm{A} 08$

2

2

Males

M-A04 2002

M-A05 2002

M-A06 2002

M-A08 2002

M-A12 2002

M-A17 2004

M-A18 2004

M-NB11 2004

$\mathrm{NB} 04 \times \mathrm{A} 12$

1

1

2

M-NB15

2004

M-NB42 2005

$\mathrm{NB} 02 \times \mathrm{A} 08$

$\mathrm{A} 22 \times \mathrm{A} 08$

2

1

1

$2 \begin{array}{ll}1 & 4 \\ 2 & 3 \\ 1 & \end{array}$

15

5

(b)

\# Offspring observed

Origin mother

Founder

Native-born

Origin father

Founder

Native-born

(c)

$\begin{array}{rrrrrl}6 & 4 & 8 & 15 & 21 & 54 \\ 6 & 4 & 3 & 7 & 5 & 25 \\ 0 & 0 & 5 & 8 & 16 & 29 \\ & & & & & \\ 6 & 4 & 8 & 15 & 5 & 38 \\ 0 & 0 & 0 & 0 & 16 & 16\end{array}$

Total \# individuals involved in mating

\# Reproducing females

4

4

4

7

11

17

Origin

Founder

Native-born

4

$4 \quad 2$

4
3

3

3
8

9

0

2

$\begin{array}{lll}3 & 8 & 8\end{array}$


Table 3 continued

\begin{tabular}{|c|c|c|c|c|c|c|c|}
\hline & \multirow[t]{2}{*}{ Parents $(\mathrm{F} \times \mathrm{M})$} & \multicolumn{5}{|c|}{ Winter period during which mating took place } & \multirow{2}{*}{$\begin{array}{l}\text { Total \# offspring } \\
\text { observed }\end{array}$} \\
\hline $\begin{array}{l}\text { Year of release } \\
\text { or estimated birth }\end{array}$ & & $2002 / 03$ & $2003 / 04$ & $2004 / 05$ & $2005 / 06$ & $2006 / 07$ & \\
\hline \# Reproducing males & & 4 & 3 & 3 & 1 & 4 & 10 \\
\hline \multicolumn{8}{|l|}{ Origin } \\
\hline Founder & & 4 & 3 & 3 & 1 & 1 & 7 \\
\hline Native-born & & 0 & 0 & 0 & 0 & 3 & 3 \\
\hline \# Matings (females) per male (min-max) & & 1 & $1-2$ & $1-2$ & 7 & $1-5$ & \\
\hline
\end{tabular}

$A$ numbers refer to founding animals, $N B$ numbers to offspring (i.e. native-born). $F$ female, $M$ male

Table 4 Summarised data on female and male reproductive success during the period July 2002-April 2008

\begin{tabular}{|c|c|c|c|c|c|c|c|c|c|c|c|c|c|}
\hline \multirow[t]{3}{*}{ Individual } & \multirow{3}{*}{$\begin{array}{l}\text { Parents } \\
(\mathrm{F} \times \mathrm{M})\end{array}$} & \multicolumn{10}{|c|}{ Male } & \multirow[t]{3}{*}{ \# Matings } & \multirow[t]{3}{*}{ \# Offspring } \\
\hline & & $\begin{array}{l}\text { M- } \\
\text { A04 }\end{array}$ & $\begin{array}{l}\text { M- } \\
\text { A05 }\end{array}$ & $\begin{array}{l}\text { M- } \\
\text { A06 }\end{array}$ & $\begin{array}{l}\text { M- } \\
\text { A08 }\end{array}$ & $\begin{array}{l}\text { M- } \\
\text { A12 }\end{array}$ & $\begin{array}{l}\text { M- } \\
\text { A15 }\end{array}$ & $\begin{array}{l}\text { M- } \\
\text { A18 }\end{array}$ & M-NB11 & M-NB15 & M-NB42 & & \\
\hline & & & & & & & & & $\mathrm{NB} 04 \times \mathrm{A} 12$ & $\mathrm{NB} 02 \times \mathrm{A} 08$ & $\mathrm{~A} 22 \times \mathrm{A} 08$ & & \\
\hline
\end{tabular}

Female

F-A00

F-A01

F-A02

F-A03

F-A17

F-A19

F-A20

F-A22

F-A23

F-NB02 A03 $\times$ A12

F-NB04 A02 $\times$ A06

F-NB07 A03 $\times$ A12

F-NB16 A02 $\times$ A08

F-NB17 A02 $\times$ A08

F-NB19 A19 $\times$ A18

F-NB22 $\quad \mathrm{NB} 07 \times \mathrm{A} 08$

F-NB32 NB07 $\times$ A08

\# Matings

\# Offspring

2

$\begin{array}{rrrr}1 & & 1 & \\ & 1 & 4^{2} & 1 \\ & & & 3^{2}\end{array}$

$\begin{array}{ll}2 & 1 \\ 3^{2} & \\ 3^{2} & \end{array}$

Indicated are the observed number of offspring of each female or male and the parentage of the offspring. $A$ numbers refer to founding animals, $N B$ numbers to native-born (=offspring). $F$ female, $M$ male. Superscripts indicate the number of matings of the same combination (i.e. different years)

potential to distinguish closely related genotypes. In contrast to most other noninvasive genetic studies, we had the advantage of working with a closed population originating from a limited number of founders that had been genotyped beforehand. We could therefore even permit uncertain or wrong scoring when interpreting our data. The fact that our $P_{(\mathrm{ID}) \text { sib }}$ values ranged from $1.9 \times 10^{-3}(2002 / 03)$ to
$2.1 \times 10^{-3}$ (based on 7 loci) or $1.4 \times 10^{-5}$ (based on 15 loci) $(2007 / 08)$ indicates that the number of loci we used was sufficient to differentiate between individuals, juveniles and even siblings of the second and third generations. We followed the so-called matching approach (Creel et al. 2003), allowing a maximum of one mismatch to be scored as an identical genotype when we did the initial typing with 


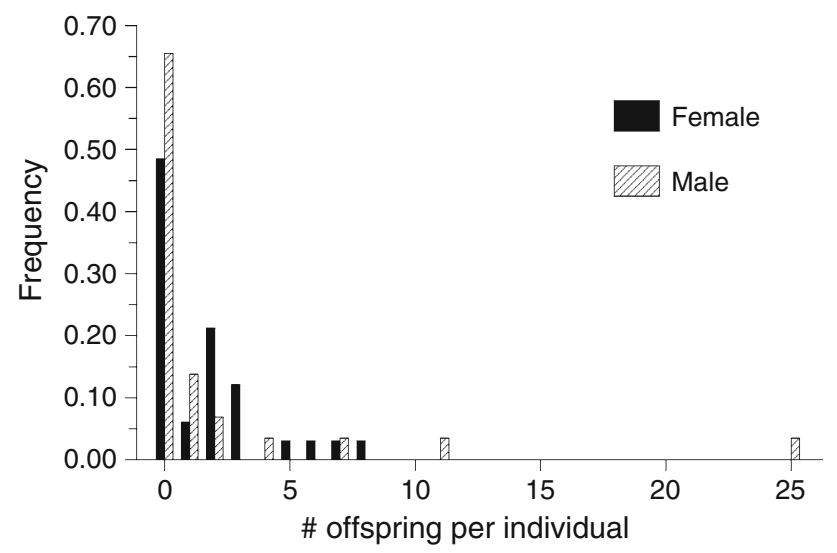

Fig. 2 Frequency distribution of the reproductive success of females and males during the period 2002-2008

Table 5 Fate of the individuals since the start of the reintroduction programme in 2002, grouped by origin (founder or native-born) and sex

\begin{tabular}{lccccc}
\hline & \multicolumn{2}{l}{ Status (1 April 2008) } & Total & Fraction alive \\
\cline { 2 - 4 } & Alive & Dead & Unknown & & \\
\hline Founders & & & & 20 & 0.30 \\
Female & 6 & 6 & 8 & 10 & 0.00 \\
Male & 0 & 5 & 5 & 30 & 0.20 \\
Total & 6 & 11 & 13 & & \\
Native-born & & & & 23 & 0.78 \\
Female & 18 & 3 & 2 & 31 & 0.29 \\
Male & 9 & 17 & 5 & 54 & 0.50 \\
Total & 27 & 20 & 7 & & \\
\hline
\end{tabular}

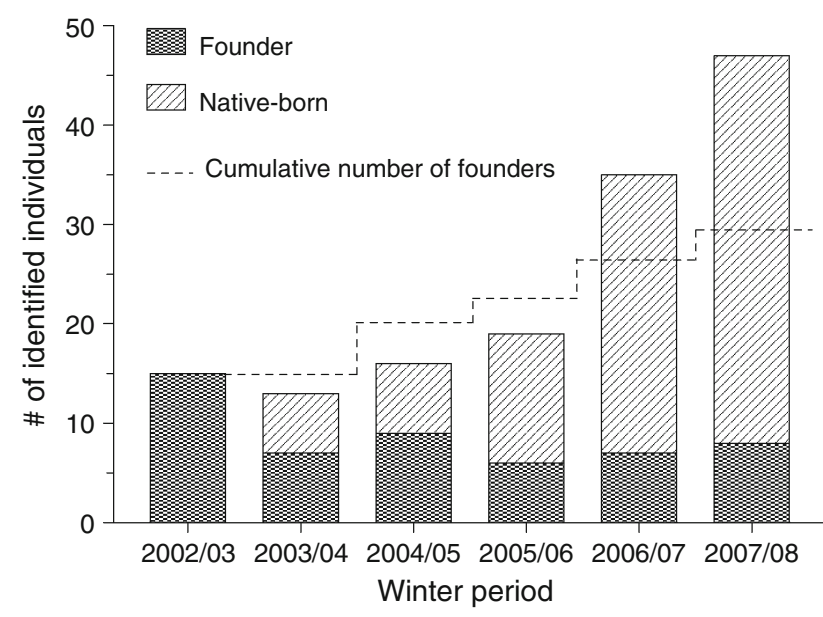

Fig. 3 The development and composition of the reintroduced Dutch otter population: the number of animals identified and their origin, either a founding animal or offspring born in the release area (nativeborn) during subsequent winters. The dotted line indicates the cumulative number of animals released during the period 2002-2008 seven microsatellites. Subsequently, we located the geographical position for the samples for which we allowed a mismatch and checked whether it fell within the area of the assigned known individual or assigned parents in case of native-born individuals. When there was a big discrepancy between the two geographical locations, the sample was processed for another set of microsatellite loci, as control. We are therefore confident that we did not overestimate population abundance through spraint genotyping. On the contrary, we most likely underestimated the current population size because we only detected $76 \%$ of the offspring through spraint genotyping (Table $2 \mathrm{a}$ ). The remaining $24 \%$, mostly subadult males, only became apparent when discovered dead and delivered to Alterra for post mortem analysis (Table 2b). Based on the placental scars of dead adult females delivered to Alterra we estimated the number of offspring per female to be $2.2(n=4)$. The latter value is close to the 2.3 newborn per female reported by Hauer et al. (2002b) for a German population. Since we inferred 30 matings (Table 4), this would give rise to 66-69 nativeborn offspring while we observed only 54 offspring (Table 4). Therefore, we suspect that we have underestimated the current population size by at least $20 \%$.

Simulations with the CAPWIRE program (Miller et al. 2005), that takes into account capture heterogeneity among individuals based on spraint genotyping, indicated that the expected number of observed genotypes during winter 2007/ 08 was 56 (confidence limits 49-67); on the basis of the genetic profiles we identified 47 genotypes (Fig. 3). This also suggests that we are underestimating the current density.

Reproductive success and dominance hierarchies

Faecal genotyping has been used frequently in recent years for studying otter distribution and abundance (Arrendal et al. 2007; Dallas et al. 2003; Ferrando et al. 2008; Hájková et al. 2008; Hung et al. 2004; Lanszki et al. 2008). Here we also report on the recruitment of offspring into the population. We were able to detect 54 offspring, and deduced that founder females were reproducing successfully within 4 months of their release. We also found evidence for second-generation breeding within 4 years (males NB11 and NB15 mating with female offspring; Table 4). The involvement of native-born individuals in reproduction is one of the criteria of the short-term success of reintroduction efforts (IUCN 1998; Morell 2008; Seddon et al. 2007).

Descriptive field studies suggest that the social system of Eurasian otters consists of female territories and independent, larger male territories (Erlinge 1968; Kruuk 2006). Our genetic data on the reproductive success of males and females confirm these observations, since (i) in contrast to the females, only a limited number of males contributed to reproduction (Table 3), (ii) among these 
males there was a hierarchy of dominance, with a few highly productive males (A08 and NB15; Table 4; Fig. 2), and (iii) males mated with several females during one season (Table 3c). As a consequence, male reproductive success is highly skewed and will cause increased relatedness in our reintroduced population.

The dominance of a few males is also reflected in the distribution patterns of individual animals (data not shown) and the number of spraints collected per individual. Males with large territories were represented more frequently in our spraint surveys-a finding that agrees with previous studies (see Hájková et al. 2008). At the start, in 2002, A12 was the dominant male; he was succeeded by A08 in the Weerribben (winter 2005/06) and by A18 in the Wieden (winter 2004/05) (Table 2a). After A18 died, A08 took control over the whole release area during winter 2005/06, having relinquished the Weerribben in 2006/07 to his son NB15 who then became the most dominant male (Table 2a). The number of dominant males dividing up the release area is much lower than expected. Currently only 2-3 adult males occupy the area, whereas it was expected that the area was big enough for 5-6 males.

The dominant behaviour of adult males caused the exodus of juvenile and subadult males-a pattern frequently observed in otters (Kruuk and Moorehouse 1991) and other carnivores (Creel and MacDonald 1995). Juvenile males were usually observed at the borders of the release area, occasionally roaming the area and waiting for an opportunity to enter. When A08 disappeared from the Wieden his place was taken over by NB30 (winter 2007/ 08; Table 2a). However, while roaming through his newly acquired territory this male was killed in a road traffic accident before he had the chance to reproduce. To our knowledge we are the first to document the social behaviour of the otter in such detail and this was only feasible because of the detailed results obtained through noninvasive genetic analyses.

\section{Effective population size}

A consequence of the social system and the skewed reproductive success is that the average number of individuals $(N)$ counted in a population does not necessarily reflect the true population size. To estimate the effective number of breeding individuals $\mathrm{Ne}$, i.e. the number of individuals in an ideal population (random mating, equal sex contributions to the next generation) that gives rise to the same observed variation, corrections must be made to the number counted for the juvenile/adult ratio, the variation in numbers in time, the sex ratio and the non-random distribution of family size (Falconer and MacKay 1996). $\mathrm{Ne}$ is the most reliable indicator of the effective number of breeding individuals in a population. When correcting for variation in family size $\mathrm{Ne}$ is estimated by $\mathrm{Ne} \approx 8 \mathrm{~N} /$ $\left(V_{f}+V_{m}+4\right)$, where $N$ is the observed number of adults and $V_{f}$ and $V_{m}$ are the observed variances in family size for females and males. In an ideal population both $V_{f}$ and $V_{m}$ are equal to 2 , thereby resembling a poisson distribution of reproductive success with a mean of 2 offspring per mating (Falconer and MacKay 1996). Using the variance in reproductive success as a measure for variance in family size, $\mathrm{Ne}$ was estimated as $8 \mathrm{~N} /(4+4.92+24.71)$; thus, about $24 \%$ of the observed number. Since the main cause of this reduction is the high variance in male reproductive success (Fig. 2), which is a consequence of the social system of otters, it is difficult to take measures to reduce the large variance in male reproductive success. The real effective number will be even lower after correcting for the other factors. Thus, despite the increase observed in the number of animals in the population, the population is still vulnerable because the effective population is small.

Our findings are in line with the observations on other species. Frankham (1995) estimated the $\mathrm{Ne} / \mathrm{N}$ ratio in natural populations of animals to be 0.11 and argued that the main determinants of the reduction were variation in numbers between years and the variance in effective family size. The variation in family size reduced effective population sizes to an average of $54 \%$ of the census sizes. Heywood (1986), though working with plant populations, estimated the $N e / N$ ratio to be 0.34 and, interestingly, demonstrated that the main contributor to this reduction was the large variance in seed production among individual plants.

Sex-biased dispersal, mortality and the modification of the release plan

The genetic results revealed that mortality among young males was much higher than their female siblings (Table 5). Road traffic accidents turned out to be responsible for $87 \%$ of the otters found dead and most of the victims were males found outside the release area (within a radius of ca. $50 \mathrm{~km}$ around the release area). Apparently, juvenile females remain in the release area, while juvenile males leave the area. This pattern is confirmed by the geographical distribution of spraint observations (data not shown): juvenile females stay close to the territories of their mothers and have a high incidence of breeding next to the mother's territory in subsequent years. The juvenile males, on the other hand, are forced out of the area by the dominant males (cf. Kruuk and Moorehouse 1991).

Our results show that traffic is the main threat to the reintroduced otters, as has been found in other studies throughout Europe (Hauer et al. 2002a; Kruuk and Conroy 1991; Sommer et al. 2005). This emphasises the need for increased habitat connectivity and should receive highest 
priority in the near future, to ensure that otters are encouraged to migrate to suitable areas outside the study area, as otherwise a new isolated otter population will have been created.

Because of the sex-biased dispersal it was decided to change the release strategy during the course of the project. Since the juvenile females stayed in the release area and the juvenile males were forced out of the area, it was decided that new releases in the adjacent satellite areas like the Oldematen and the Lindevallei (Fig. 1) should be only of females, as this might discourage the males from travelling further away from the release area.

The need for post-release monitoring in reintroduction studies

As pointed out by Seddon et al. (2007), most of the information on reintroduction programmes consists of descriptive accounts and retrospective analyses. The research questions addressed have largely been driven by the monitoring data available, instead of the monitoring being driven by the questions. Before starting the monitoring we discussed which information would be essential to field managers and how this could best be obtained. We decided to use noninvasive genetic monitoring as our main strategy, and to use traditional telemetry only to detect the initial establishment of the founders. Typing all founding animals before release provided us with a base reference population from the outset. This individual-oriented approach is feasible, especially in reintroduction studies which are usually based on a limited number of individuals; it will provide information on processes related to small populations. During the first 3 years of the reintroduction project the project had a bad press because the general public did not see the otters and the media reported traffic incidents and the low number of identified individuals (Fig. 3). It was not until we had demonstrated that (i) otters were reproducing (Table 3), (ii) the number of individual otters identified exceeded the number of otters released (Fig. 3), and (iii) we were on course for a new Dutch population (Fig. 3), that attitudes changed. The otter population did not start to grow until after the offspring of the founders took part in the reproduction (Fig. 3). Only genetics could reveal these details. The lesson is that, when reintroducing animals, one should be prepared for a slow start and accept losses due to mortality. These processes are inevitable.

The future of the Dutch otter population

Despite the initial success in achieving a growing population and detecting mating between native-born individuals, both of which are short-term criteria for successful reintroductions (Morell 2008; Seddon et al. 2007), the future of the Dutch otter population remains uncertain. We have created a new, small and isolated population with a low effective population size. This population is currently approaching the maximum carrying capacity of the release area. The original plan aimed at a connection with a second settled population in nearby wetlands. This has not yet been achieved, and consequently many animals are killed in traffic incidents when they move away from the current population. Moreover, the otters have their own strategy: only a few males dominate the reproductive process, thereby lowering the effective population size and increasing relatedness and the occurrence of inbreeding. Whether inbreeding will have an effect on the current population is yet unknown, since no data are available on the occurrence of inbreeding depression in otters. However, data from other large mammal species (Laikre 1999; Liberg et al. 2005) indicate that inbreeding effects can be substantial. To counteract possible negative effects of inbreeding, the preferred option would be to establish connection with other or newly founded nearby populations. If this is not feasible, the only option might be to regularly introduce a new unrelated male into the current population.

\section{Conclusions}

Noninvasive genetic monitoring has given us insight into the hidden life of otters and has proved to be a valuable tool for conservation purposes. Traditional monitoring techniques would not have provided us with an as detailed picture of the reintroduced otter population. The results on the differences in social and territorial behaviour between males and females forced us to reconsider our initial release plan and also indicate that however well the introduction methods are prepared for by developing a scientific and socio-economic strategy, there will be surprises because the key players have a strategy of their own (cf. Morell 2008). Our studies confirm the need for intensive post-release monitoring of reintroduced species (cf. Armstrong and Seddon 2008).

Acknowledgments The site management organisations Staatsbosbeheer, Fryske Gea and Vereniging Natuurmonumenten are acknowledged for their hospitality and assistance in the field. We thank the many students who took part in the field work. This project would have been impossible without the help of many people involved in capturing wild otters in Belarus, Latvia and Poland under the coordination of the Dutch Otterstation Foundation (SON) and without the help of Alfred Melissen for making otters available from European breeding programmes. Funding was obtained from the Ministry of Agriculture, Nature and Food Quality (BO-02-013; Active policy on species management). The preparation of this manuscript was encouraged by visiting the ESF Conservation Genetics Network 
meeting in Trondheim in 2009. The finishing touch was made possible by the KB1-Veerkracht (KB-01-007) priority programme. Joy Burrough corrected the clogged English.

Open Access This article is distributed under the terms of the Creative Commons Attribution Noncommercial License which permits any noncommercial use, distribution, and reproduction in any medium, provided the original author(s) and source are credited.

\section{References}

Allendorf FW, Luikart G (2006) Conservation and the genetics of populations. Wiley-Blackwell, London

Armstrong DP, Seddon PJ (2008) Directions in reintroduction biology. Trends Ecol Evol 23:20-25

Arrendal J, Vilà C, Björklund M (2007) Reliability of noninvasive genetic census of otters compared to field censuses. Conserv Genet 8:1097-1107

Beheler AS, Fike JA, Dharmarajan G, Rhodes OE, Serfass TS (2005) Ten new polymorphic microsatellite loci for North American river otters (Lontra canadensis) and their utility in related mustelids. Mol Ecol Notes 5:602-604

Blouin MS (2003) DNA-based methods for pedigree reconstruction and kinship analysis in natural populations. Trends Ecol Evol 18:503-511

Bonin A, Bellemain E, Eidesen PB, Pompanon F, Brochmann C, Taberlet P (2004) How to track and assess genotyping errors in population genetics studies. Mol Ecol 13:3261-3273

Creel S, Macdonald DW (1995) Sociality, group size, and reproductive suppression among carnivores. Adv Study Behav 24:203-257

Creel S, Spong G, Sands JL, Rotella J, Zeigle J, Joe L, Murphy KM, Smith D (2003) Population size estimation in Yellowstone wolves with error-prone non-invasive microsatellite genotype. Mol Ecol 12:2003-2009

Dallas JF, Piertney SB (1998) Microsatellite primers for the Eurasian otter. Mol Ecol 7:1248-1251

Dallas JF, Coxon KE, Sykes T, Chanin PRF, Marshall F, Carss DN, Bacon PJ, Piertney SB, Racey PA (2003) Similar estimates of population genetic composition and sex ratio derived from carcasses and faeces of Eurasian otter Lutra lutra. Mol Ecol $12: 275-282$

DeYoung RW, Honeycutt RL (2005) The molecular toolbox: genetic techniques in wildlife ecology and management. J Wildl Manag 69:1362-1384

Erlinge S (1968) Territoriality of the otter Lutra lutra L. Oikos 19:8198

Falconer DS, MacKay TFC (1996) Introduction to quantitative genetics. Longman, UK

Ferrando A, Lecis R, Domingo-Roura X, Ponsà M (2008) Genetic diversity and individual identification of reintroduced otters (Lutra lutra) in north-eastern Spain by DNA genotyping of spraints. Conserv Genet 9:129-139

Frankham R (1995) Effective population size/adult population size ratios in wildlife: a review. Genet Res 66:95-107

Gagneux P, Boesch C, Woodruff DS (1997) Microsatellite scoring errors associated with noninvasive genotyping based on nuclear DNA amplified from shed hair. Mol Ecol 6:861-868

Hájková P, Zemanová B, Bryja J, Hájek B, Roche K, Tkadlec E, Zima J (2006) Factors affecting success of PCR amplification of microsatellite from otter faeces. Mol Ecol Notes 6:559-562

Hájková P, Zemanová B, Roche K, Hájek B (2008) An evaluation of field and noninvasive genetic methods for estimating Eurasian otter population size. Conserv Genet 10:1667-1681
Hauer S, Ansorge H, Zinke O (2002a) Mortality patterns of otter (Lutra lutra) from eastern Germany. J Zool 256:361-368

Hauer S, Ansorge H, Zinke O (2002b) Reproductive performance of otters Lutra lutra (Linnaeus, 1758) in eastern Germany: low reproduction in a long-term strategy. Biol J Linn Soc 77:329_ 340

Hedmark E, Flagstad O, Segerstrom P, Persson J, Landa A, Ellegren $\mathrm{H}$ (2004) DNA-based individual and sex identification from wolverine (Gulo gulo) faeces and urine. Conserv Genet 5:405410

Heywood J (1986) The effect of plant size variation on genetic drift in populations of annuals. Am Nat 127:851-861

Huang CC, Hsu YC, Lee LL, Li SH (2005) Isolation and characterization of tetramicrosatellite DNA markers in the Eurasian otter (Lutra lutra). Mol Ecol 5:314-316

Hung CM, Li SH, Lee LL (2004) Faecal DNA typing to determine the abundance and spatial organisation of otters (Lutra lutra) along two stream systems in Kinmen. Anim Conserv 7:301-311

IUCN (1998) Guidelines for re-introductions. Prepared by the IUCN/ SSC Re-introduction Specialist Group. IUCN. (http://www. iucnsscrg.org)

Jones AG, Ardren WR (2003) Methods of parentage analysis in natural populations. Mol Ecol 12:2511-2523

Kendall KC, Stetz JB, Boulanger J, MacLeod AC, Paetkau D, White GC (2009) Demography and genetic structure of a recovering grizzly bear population. J Wildl Manag 73:3-17

Kohn MH, Wayne RK (1997) Facts from feces revisited. Trends Ecol Evol 12:223-227

Kohn MH, York EC, Kamradt DA, Haught G, Sauvajot RM, Wayne RK (1999) Estimating population size by genotyping faeces. Proc R Soc, Ser B: Biol Sci 266:657-663

Kruuk H (1992) Scent marking by otters (Lutra lutra): signalling the use of resources. Behav Ecol 3:133-140

Kruuk H (2006) Otters: ecology, behaviour and conservation. Oxford University Press, Oxford

Kruuk H, Conroy JWH (1991) Mortality of otters (Lutra lutra) in Shetland. J Appl Ecol 28:83-94

Kruuk H, Moorehouse A (1991) The spatial organisation of otters (Lutra lutra) in Shetland. J Zool 224:41-57

Laikre L (1999) Conservation genetics of Nordic carnivores: lessons from zoos. Hereditas 130:203-216

Lanszki J, Hidas A, Szentes K, Révay T, Lehoczky I, Weiss S (2008) Relative spraint density and genetic structure of otter (Lutra lutra) along the Drava River in Hungary. Mamm Biol 73:40-47

Liberg O, Andren H, Pedersen HC, Sand H, Sejberg D, Wabakken P, Akkesson M, Bensch S (2005) Severe inbreeding depression in a wild wolf Canis lupus population. Biol Lett 1:17-20

Mason CF, MacDonald SM (1986) Otters: ecology and conservation. Cambridge University Press, Cambridge

Miller CR, Joyce P, Waits LP (2002) Assessing allelic dropout and genotype reliability using maximum likelihood. Genetics 160:357-366

Miller CR, Joyce P, Waits LP (2005) A new method for estimating the size of small populations from genetic mark-recapture data. Mol Ecol 14:1991-2005

Mills LS, Citta JJ, Lair KP, Schwartz MK, Tallmon DA (2000) Estimating animal abundance using non-invasive DNA sampling: promise and pitfalls. Ecol Appl 10:283-294

Morell V (2008) Into the wild: reintroduced animals face daunting odds. Science 320:742-743

Nichols JD, Williams BK (2006) Monitoring for conservation. Trends Ecol Evol 21:668-673

Palomares F, Godoy JA, Piriz A, O’Brien SJ, Johnson WE (2002) Faecal genetic analysis to determine the presence and distribution of elusive carnivores: design and feasibility of the Iberian lynx. Mol Ecol 11:2171-2182 
Parsons KM, Dallas JF, Claridge DE, Durban JW, Balcomb KC, Thompson PM, Noble LR (1999) Amplifying dolphin mitochondrial DNA from faecal plumes. Mol Ecol 8:1753-1768

Piggott MP, Taylor AC (2003) Remote collection of animal DNA and its applications in conservation management and understanding the population biology of rare and cryptic species. Wildl Res 30:1-13

Prugh LR, Ritland CE, Arthur M, Krebs CJ (2005) Monitoring coyote population dynamics by genotyping faces. Mol Ecol 14:15851596

Roos A, Greyerz E, Olsson M, Sandegren F (2001) The otter (Lutra lutra) in Sweden-population trends in relation to DDT and total PCB concentrations during 1968-99. Environ Pollut 111:457-469

Schwartz MK, Tallmon DA, Luikart G (1999) Using genetics to estimate the size of wild populations: many methods, much potential, uncertain utility. Anim Conserv 2:321-323

Schwartz MK, Luikart G, Waples RS (2007) Genetic monitoring as a promising tool for conservation and management. Trends Ecol Evol 22:25-33

Seddon PJ, Armstrong DP, Maloney RF (2007) Developing the science of reintroduction biology. Conserv Biol 21:303-312

Sommer R, Griesau A, Ansorge H, Priemer J (2005) Daten zur Populationsökologie des Fischotters Lutra lutra (Linnaeus,
1758) in Mecklenburg-Vorpommern. Beiträge zur Jagd-und Wildforschung 30:253-271

Taberlet P, Luikart G (1999) Noninvasive genetic sampling and individual identification. Biol J Linn Soc Lond 68:41-55

Taberlet P, Griffin S, Goossens B, Questiau S, Manceau V, Escaravage N, waits LP, Bouvet J (1996) Reliable genotyping of samples with very low DNA quantities using PCR. Nucleic Acids Res 16:3189-3194

Taberlet P, Waits LP, Luikart G (1999) Noninvasive genetic sampling: look before you leap. Trends Ecol Evol 14:323-327

van Wijngaarden A, van de Peppel J (1970) The otter, Lutra lutra (L.), in The Netherlands. Lutra 12:3-70 (in Dutch with an English summary)

Waits LP, Paetkau D (2005) Noninvasive genetic sampling tools for wildlife biologists: a review of applications and recommendations for accurate data collection. J Wildl Manag 69:1419-1433

Waits LP, Luikart G, Taberlet P (2001) Estimating probability of identity among genotypes in natural populations: cautions and guidelines. Mol Ecol 10:249-256

Wayne RK, Morin PA (2004) Conservation genetics in the new molecular age. Front Ecol Environ 2:89-97 